\title{
Passenger representation within the light-handed regulation - Insights from the Australian air transport market
}

\author{
Beat Kistler ${ }^{\mathrm{a}}$, Jakob Trischler ${ }^{\mathrm{b}}$ and Gui Lohmann ${ }^{\mathrm{a} *}$ \\ ${ }^{a}$ Griffith Aviation, Griffith University, 170 Kessels Road, Nathan, 4111, QLD, Australia; \\ ${ }^{b}$ Karlstad University, CTF Service Research Center, Universitetsgatan 2, 65188 Karlstad, \\ Sweden \\ * g.lohmann@griffith.edu.au
}

\section{Acknowledgements}

The authors would like to acknowledge the financial support received by Queensland Airports Ltd (QAL) for this research as part of a university-industry collaboration scheme grant. In particular, they are grateful to Dennis Chant (QAL's former Managing Director), Craig Shaw (QAL Services' former COO), Chris Mills (QAL's current Managing Director), Amelia Evans (QAL's current CFO). The usual disclaimer applies. 


\title{
Passenger representation within the light-handed regulation - Insights from the Australian air transport market
}

\begin{abstract}
This article critically reviews the representation of passengers within the light-handed regulation (LHR) that has been in place in the Australian air transport market since 2002. The focus is the commercial negotiations between airlines and airports concerning investments that affect passengers as key stakeholders, end-users, and payers. The article draws on literature on consumer representation and willingness to pay, as well as data from 21 in-depth interviews. The findings suggest that within the current arrangement, passengers are dependent on airlines as their representatives, although their interests may differ concerning investments in airport infrastructure and services. This dependency is leveraged by the current airline duopoly in the Australian domestic air transport market because passengers have no transport alternatives among which to choose. Airports charging passengers their fees (and eventually negotiating prices for improved services) directly is not deemed a suitable option because it could increase the airports' market power and affect the passenger experience negatively. Recommendations, such as involving an independent representation body and diversifying service provision at the airport, are discussed as possibilities for increasing passengers' influence.
\end{abstract}

Keywords: Australian air transport market, consumer representation, light-handed regulation, willingness to pay. 


\section{Introduction}

Deregulation has provided many opportunities for the air transport sector, particularly regarding reducing costs, diversifying service provision and utilising synergy effects with key stakeholders (Bilotkach, Clougherty, Mueller \& Zhang, 2012; Fu, Homsombat \& Oum, 2011). In most regulatory regimes, however, the voice of the passenger as the end-user is neglected, particularly regarding their specific needs and willingness to pay for new infrastructure developments (Schiefelbusch, 2005; Thao, Wegelin \& von Arx, 2017). This is specifically the case in markets that lack competition or substitutes (Hanson, 1999), as is the case in the Australian domestic air transport market. In Australia, with very few exceptions (e.g., Brisbane and Gold Coast), the majority of the population in large cities has only one airport option to fly from (in some cases, airports are available but with few commercial route options), coupled with the domination of the domestic market by a duopoly of airlines. Alternative means of intercity transport such as train and coaches are scarce and highly inefficient. As a result, there is a considerable risk that the passengers' voices are not appropriately considered in negotiations concerning investments in airport infrastructure and services. For example, while passengers can typically choose freely between different services provided by an airline (e.g., business or economy class), they have little say about the services provided by an airport.

The weak position of the passenger as the customer and key stakeholder is problematic because the Australian air transport market is not regulated per se but merely monitored as part of the light-handed regulation (LHR) (Forsyth, 2008; Littlechild, 2012). This framework encourages commercial negotiations between airports and airlines (Arblaster, 2017). The passenger is not represented during these negotiations, however, and any increases in airport pricing that result from these negotiations are passed on to them directly. Consequently, during the negotiations, airlines might primarily focus on their specific interests (e.g., maximising operational productivity) rather than on those of the passengers (e.g., improving the passengers' airport experience or convenience). In turn, airports are monitored regarding their quality of service levels owing to their market power position. Airports must negotiate and reach an agreement with airlines on any possible fee increases related to quality-improving airport investments (Lohmann \& Trischler, 2017). If no agreement is 
reached, airports must either delay the investment or find alternative sources of funding (as was the case with the construction of the new runway at Brisbane Airport).

In line with Yang and Fu's (2015, p. 122) recommendation that LHR is "worth preserving subject to monitoring and continuous improvement", this study critically reviews the representation of passengers within the Australian air transport market. The focus is thus on passenger representation in commercial negotiations between airlines and airports as is defined in the following overarching research question:

RQ1: How can passengers be meaningfully represented in negotiations between airports and airlines?

Addressing this research question is important because passengers, as a key stakeholder, should have a voice in investment decisions that affect them as end-users. $R Q 1$ is underpinned by two sub-questions focusing on investigating passenger representation in the context of the LHR, as it is instantiated in the Australian air transport market $(R Q 1 a)$, as well as exploring possible alternatives to the current charging system. This includes the consideration of direct charge in combination with the passengers' willingness to pay as a possible way to bypass the negotiations with airlines, and in so doing, give the passengers the possibility to more directly influence decisions regarding new infrastructure developments $(R Q 1 b)$ :

RQ1a: Within the current LHR design, who represents passengers during negotiations between airports and airlines?

RQ1b: Can direct charge (i.e., airports directly charging passengers for airport fees) be an alternative to the current charging system?

Derived from the evaluation of the current literature and the analysis of data generated through indepth interviews with stakeholders and experts in the field, this paper investigates the perception of the current negotiation and charging framework that is in place in the Australian air transport market. With a specific focus on passenger representation, the study additionally explores possible new 
mechanisms that can help policymakers to more effectively incorporate the voice of the passenger, including the consideration of their specific needs and willingness to pay.

\section{Literature Review}

\subsection{Consumer representation in regulatory environments}

Consumer representation in a regulatory environment concerns procedures and structures that allow consumers, including passengers, "to express their interest directly, efficiently and in a timely manner" (Schiefelbusch, 2005, pp.263-4). In cases where a market is sufficiently competitive, it is questionable whether a sector-specific independent consumer body is needed, given that consumers can freely choose from a selection of options (Harker et al., 2006). It puts the consumer in a stronger position because they have a choice and can make a decision based on their specific needs and preferences. This market mechanism may not always function, however, as the consumer might not possess all of the information needed or may simply lack appropriate choice or alternatives owing to market entry barriers such as scarce resource availability, or a lack of substitutes (Hanson, 1999; Porter, 1979). For example, in privatised utilities or sectors (e.g., telecommunication, energy, and transportation), consumers are typically represented by independent bodies to give them a stronger position in, e.g., negotiations with the respective service provider (Thao, Wegelin \& von Arx, 2017).

Consumer representation can be facilitated by consumer bodies in the following five ways (Cartledge, 1992; Harker, Mathieu \& Waddams Price, 2006): 1) ensuring that the consumer's voice is heard, especially in markets where there is a monopoly; 2) protecting the consumer's ability to choose and switch between products or services; 3 ) advising consumers in disputes with the service provider; 4) supervising the sector's regulator, and as such, serving as a voice for the media, government and public; and 5) monitoring and reporting on the quality of service provided to the consumer. An illustrative example of a consumer representation body covering the first three roles listed above is the Communications Consumer Panel in the UK. Established under the Communication Act 2003, this panel is an independent policy advisory body that represents consumer interests in telecommunications, broadcasting and spectrum markets (Communications Consumer Panel, 2016). 
While the stated objective of this panel is to protect and promote consumers' interests, Tambini (2012) points out that such bodies might, in fact, be semi-independent (e.g., their members are selected by the regulator, with the panel being dependent on the regulator's budget allocations). This arrangement means that some consumer representation bodies may not be fully independent of the government or the regulator itself. In turn, in Australia, the Australian Competition and Consumer Commission (ACCC) acts as the national competition regulator concerned with promoting competition and fair trade in markets to benefit consumers, businesses, and the community (ACCC, 2017). Its main responsibility is “...to ensure that individuals and businesses comply with Australian competition, fair trading, and consumer protection laws - in particular, the Competition and Consumer Act 2010" (ACCC, 2017, p.1). While the ACCC is promoting competition and fair trade as well as protecting the consumer, its role is not to promote or represent the consumer's voice.

Consumer representation bodies are also common in the air transport sector, specifically in countries where the market is less regulated (Adler, Forsyth, Mueller \& Niemeier, 2015; Thao, Wegelin \& von Arx, 2017). For example, in the UK, the Civil Aviation Authority (CAA UK) has set up a semi-independent consumer panel (i.e., with members appointed and the panel funded by the regulator) to scrutinise and challenge the work of the CAA UK and to be a 'champion' of the consumers' interest (CAA Consumer Panel, 2013; 2017). Notably, the CAA UK calls for the greater involvement of passengers because of concerns that the mutual interests of airports and incumbent airlines might not be in passengers' best interests (see Littlechild, 2018 for a recent review). In Australia, the ACCC indirectly represents the consumer by monitoring the prices and quality of service of the four largest airports (i.e., Sydney, Melbourne, Brisbane and Perth) (Trischler \& Lohmann, 2018). Also, in 2012, the Airline Customer Advocate (ACA) was established to facilitate an effective complaint resolution process between airline customers and the five major Australian airlines: Jetstar, Qantas, Regional Express (REX), Tigerair and Virgin Australia (ACA, 2017). The ACA's role is "to represent the interests of airline customers of the participating airlines and play a leading role in customer advocacy within the Australian airline industry" (ACA, 2017, p.1). Thus, while the ACA represents a service provided indirectly by the airlines to their passengers through a 
third-party body to resolve complaints more effectively (i.e., third role of consumer representation), it does not necessarily act in the passengers' interest or represent the passengers' voice.

The above review shows that consumer representation is common across industries, including the air transport sector. There are often limitations in the way consumers are represented (i.e., the true independency of the bodies), as well as in what areas consumers are represented (e.g., complaints, consumer protection, promoting competition). As underscored by Thao, Wegelin and von Arx (2017), although various forms of consumer representation have been established due to ongoing regulatory reforms, only some are effective in safeguarding passengers' interests. Focusing on the Australian market, no representative bodies could be identified that represent the passengers' voice (i.e., the first role of consumer representation) and give them the opportunity to express their opinions and preferences in the negotiation processes between airlines and airport operators. This lack of representation is a common problem in the transportation sector, where owing to a monopoly position held by the transport provider, "customers cannot express dissatisfaction with the service on offer by switching to another operator" (Schiefelbusch, 2005, p.261). The same is true for the Australian air transport market: owing to the long distances between the major population areas as well as the lack of alternatives such as high-speed rail, the customer has limited possibilities in choosing or switching between different transport modes or airports (Arblaster, 2016). The following section examines this issue in more detail to provide a better understanding of the Australian air transport market and its implication for consumer representation during negotiations between airports and airlines, which is the focus of the present research.

\subsection{Background of the Australian airport regulation}

The Australian air transport market is subject to an LHR framework (Adler et al., 2015), which “...places no immediate constraints on aeronautical charges but monitors prices intending to "taking action' if prices are judged to be too high" (Gillen, 2011, p.9). This means that the airport operators and airlines negotiate prices in the form of commercial relationships (e.g., major infrastructure developments, service improvements, airport charges) without the intervention of a regulator 
(Arblaster \& Hooper, 2015; Lohmann \& Trischler, 2017). The intention of the Australian Government is to keep administrative costs low while facilitating an environment that allows good economic outcomes (Arblaster, 2014). Nevertheless, the four major airports in Australia in Sydney, Melbourne, Brisbane, and Perth are subject to some form of regulation and oversight (Littlechild, 2012). This regulation includes the monitoring of both prices and quality of service on an annual basis by the ACCC (Trischler \& Lohmann, 2018).

Commercial negotiations are the omnipresent interaction between entities in market economies attempting to provide certainty about their relationship based on negotiated contracts. The more bargaining power a party has, the more likely it is that it will have an advantageous outcome over the other party (Productivity Commission, 2011). For example, in Australia, airports may be in an advantageous position because airlines do not have access to secondary airports as they do in other parts of the world (Forsyth, 2004; 2008). Such market power potentially enables airports to raise prices to cover the costs of any investments they make and put airlines in a 'take it or leave it' position (Arblaster, 2014). Additionally, the market power possessed by airports might lead to a holdup problem where airlines refrain from sunk investments because of the risk that the airport could raise its prices to extract some of the value of that investment (Biggar, 2012; D'Alfonso \& Nastasi, 2014; Serebrisky, 2003). Recognising the possibility of the abuse of market power, the ACCC has put into place price and quality of service monitoring (ACCC, 2014). Within Australia's LHR, each airline negotiates directly with the airport operator in the absence of a sector-wide template for commercial agreements. In its current role, the ACCC does not possess the power to intervene in the negotiations (Lohmann \& Trischler, 2017). Hence, it is constructively foreclosed from covering a key role of consumer representation, namely, representing the passengers' voice (Harker et al., 2006). Instead, the ACCC reports its analysis to the government, which in the case of market power abuse, can intervene with stronger regulation (Arblaster, 2016).

Within the LHR, it is not defined who represents the passengers' voice during the commercial negotiations between the airport operators and airlines. Through their market power position, airports do not represent passengers because even the possibility of generating concession revenues from 
activities such as retailing, car parking and catering might not deter an airport from increasing prices or decreasing quality of service (Fu et al., 2011). Notably, airlines charge the negotiated and agreed airport charges to the passengers as part of their ticket price (Productivity Commission, 2011). Therefore, it might be argued that airlines are indirectly representing the passenger during the negotiations with airports. This argument, however, is open for discussion during the negotiations because the airlines' interests might not be in line with those of the passengers (Littlechild, 2018). To illustrate, while passengers might prefer investments that improve perceived service quality such as air bridges, convenient connections between terminals, or improved access to the airport (e.g., kerbside, traffic management), the airlines' primary focus might be on investments that improve their operational procedures and efficiency at the airport.

Furthermore, airports and airlines seek to form long-term vertical relationships to leverage synergy effects and protect their investments (D'Alfonso \& Nastasi, 2014; Yang, Zhang \& Fu, 2015). These vertical relationships lead to the risk that the voice of the passengers, including their specific needs and willingness to pay, might not be appropriately considered during the commercial negotiations between airlines and airport operators. It points to the need for a new mechanism that a) constrains the advantageous position of airports and b) more effectively represents the specific interests of passengers as end-users. The following section reviews alternative charging mechanisms in relation to the concept of willingness to pay to explore opportunities for consumers to have more influence, or perhaps even a direct voice, in negotiations concerning airport investments and pricing.

\subsection{Willingness to pay, direct charge and technology disruption for airports}

Within the air transport sector, willingness to pay is "the amount that an individual is willing to pay $[\ldots]$ for changes in the levels of specific attributes associated with one or more alternatives" (Hensher, 2004 p.426). Based on their specific needs, passengers have different levels of willingness to pay, which allows airlines and airports to diversify their service offerings (Martín, Román \& Espino, 2008). For example, when buying an airline ticket, passengers, as customers of the airline and the respective departure and arrival airport, can choose between different services (e.g., first, business, or 
economy class) from the airline. In most cases, however, the passenger cannot choose between services provided by the airport (e.g., queuing time, boarding procedure, quality of the facility). One notable exception is Schiphol Airport (Amsterdam), which offers fast security and border clearance as part of a membership arrangement that also includes lounge access or priority parking (Schiphol, 2017). These diversified service offerings are directly charged by the airport to the passenger, either on a per-use basis or through an annual membership (loyalty program) (Graham, 2014).

Recent research suggests that service diversification is becoming an increasingly important topic for airports (see Malina, Albers \& Kroll, 2012 for incentive programs of European airports). For example, Wittmer and Maurer (2015) compared several airport loyalty programs in Europe and provided a ranking of services that are rated as most important to passengers. Services related to travel efficiency (e.g., fast-track security or priority check-in) were ranked most important and passengers indicated that they are willing to pay a higher price for a diversified service offer. Providing such diversified service, however, would require that the airport operator bypass the airport charges negotiations with the airlines by, for example, directly charging passengers. Typically, airport charges, including passenger service charges, are collected by the airlines as part of the ticket price and passed on to the airport. In some cases, the airport directly charges the passengers, as is the case at Wellington Airport in New Zealand or Denpasar Airport in Indonesia. Yet in both cases the direct charge was withdrawn, arguably owing to passenger dissatisfaction in having to pay these charges separately from their airfare purchase (De Neufville \& Odoni, 2013).

The literature provides a preliminary understanding of how consumers can be represented in markets that lack competition. In addition, the literature gives insights into the specificities of the Australian air transport market, including the LHR, and the consequences for the commercial negotiations between the airports and airlines. Finally, the literature highlights the importance of service diversification at airports to address passengers' different needs and willingness to pay. Together, these insights set an important basis for exploring possible new mechanisms that more effectively incorporate the voice of the passenger during negotiations between airports and airlines. The methodology and sample that underpin this exploration are described next. 


\section{Methodology}

This research uses a qualitative approach to report on the perception of passenger representation in the context of the LHR as instantiated in the Australian air transport market (RQ1a), and explore possible alternatives to the current charging system $(R Q 1 b)$. Data collection included in-depth interviews with airport and airline executives as well as with government regulatory managers, consultants and academics. In-depth interviews with selected experts are advantageous over surveys because they enable the investigator to ask probing questions, and in so doing, explore a phenomenon in detail (Yin, 2016). In addition, the involvement of experts from different backgrounds generates a more holistic picture of the underlying issues, which is important since topics surrounding public policy are often influenced by political processes and lobbying activities by different interest groups (Schiefelbusch, 2005; Trischler \& Charles, 2018).

All but two of the interviewees were located in Australia. Seven chief financial officers (CFOs) of the major Australian capital cities and regional airports as well as one from New Zealand participated in this research. The reasons for only interviewing CFOs from the various airports were: (a) CFOs are typically those involved in, and affected by, the outcomes of commercial negotiations with airlines; (b) CFOs are aware of the challenges in directly charging passengers within the current LHR framework; and (c) the data collected for this research were part of a larger project that had a particular interest in the views of airport CFOs. Representatives from the four monitored airports were included in the research sample. The research also considered the views of executives working at other airports, however, partly because they have previously worked for one of the monitored airports, and partly because they are equally knowledgeable about the LHR. Furthermore, the leading domestic airlines operating in Australia (including low-cost and regional subsidiaries) and a major international airline operating in Australia $(n=5)$ also participated in the study. The remaining interviewees included representatives from government regulatory bodies, various aviation-related associations and leading Australian academics with extensive experience in the underlying research topic $(n=9)$. 
Table 1 provides an overview of the participants who were interviewed as part of this study. A total of 21 interviews were obtained, with each semi-structured interview usually lasting between 45 and 60 minutes. Most interviews were conducted face-to-face in six different cities in Australia and one overseas location during the period March and August 2015. As shown in Table 1, the interview participants had different backgrounds and covered a wide spectrum of expertise and experience in relation to the LHR, which supports data triangulation. Importantly, this research did not aim to reflect on the individual experiences of a particular respondent and his or her organisation, for example, by identifying if respondents from a monitored airport had different views than respondents from non-monitored airports.

[Insert Table 1 about here]

A total of 17 interviewees agreed to have their interviews audio recorded. The recorded interviews were professionally transcribed and sent back to each interviewee for review and revision. In the four cases where permission was not given to record the interviews, notes were taken. A first draft of the present paper was sent to each interviewee for their consent and feedback before submitting it for publication. The set of transcribed interviews were coded using the NVivo software. The transcripts of the 17 interviews were analysed using emerging themes. Two overarching themes were identified: 'Direct charge' and 'User representation'. These overarching themes were subsequently used as the two main nodes to analyse the data. Notes from the four remaining interviewees were used to complement and support some of the results obtained. The data analysis is presented in the following section.

\section{Analysis}

Interviewees were categorised into three groups. Airline/airport lobbying and representation groups were included, respectively, under 'airlines' and 'airports', while government regulatory managers, academics and consultants were grouped as 'others'. Table 2 provides a general overview of the statements made by the interviewed key stakeholders. These statements were categorised into four 
key topic areas that draw on the research questions as defined in the introduction and the subsequent examination of the literature:

(1) The current state of passenger representation, specifically the question as to whether airlines represent passengers during commercial negotiations;

(2) The exploration of possible new ways to integrate the passengers' voice into commercial negotiations;

(3) The perception of the direct charge mechanism for airport charges; and

(4) The exploration of possible ways to adopt direct charge for diversified services.

Each of these four key topics is elaborated on in subsections 4.1 and 4.2 through an analysis of the interview data.

[Insert Table 2 about here]

\subsection{Consumer representation}

Passenger representation during commercial negotiations

All of the interviewed airline executives $(n=5)$ expressed their belief that airlines are good representatives for passengers during negotiations with the airport operators. They based their arguments on two reasons. First, the passenger experience at the airport is directly linked to the satisfaction of the service provided by the airline. Second, because passengers book their journey with the airline, the passengers also direct any complaints to them even if it is related to an airport issue. For example, one airline executive described this matter by stating that "We're well and truly seeing ourselves as representing the passenger because a good passenger experience means that they will have a good airline experience". Another airline executive elaborated on this view: "We see ourselves as representing the customers because we're the ones that have that relationship with them, they tell us when they don't like something or when something's gone wrong”. These relationships refer to the multiple interactions between passengers and the airline during the service process, including (a) pre-service encounters (e.g., booking the flight, updates on the upcoming flight, online 
check-in); (b) airport service encounters (e.g., check-in, lounge operated by the airline, terminal leased by the airline, ground personnel of the airline); (c) onboard service encounters (e.g., in-flight services, flight attendants); and (d) post-service encounters (e.g., loyalty programs).

In contrast, the interviewed airport executives $(n=6)$ revealed a different opinion on airlines being good representatives for the passengers. They argued that the airlines are only interested in negotiating the lowest price and focusing on their interest, although this might conflict with the passengers' interest. One airport CFO stated: “From their perspective, they want the lowest price they can negotiate, and if that means that there's some customer experience that's sacrificed then they would be fine with that." Another airport CFO reached a similar conclusion: "What they're negotiating for is their own economics for their particular airline.” The argument that airlines focus on their interests, which might not necessarily represent those of the passengers, is in contradiction to the statements made by the airline executives. This inconsistency was also noted by an airport executive:

\footnotetext{
“No, they're not [good representatives]. Airlines say that, but no, they're not. They put that context in as if they're acting for the good of their passengers. They're acting for [sic] the airline's behalf. There are many instances when their behaviour is actually at odds with what a passenger might require out of an airport."
}

Being 'at odds' was illustrated by an airport CFO with a specific example demonstrating why airlines might not truly represent the passengers' interest:

"They're ultimately self-interested for a start. In a lot of cases, theirs and the passengers' interests are aligned, so they pretty much line up. But then there are other times when they're quite happy not to provide the facilities and force people to queue because it suits them from their operating cost point of view." 
A representative from an airport lobbying association elaborated on this issue by describing the possible disconnect between the passengers' and airlines' interests as a logical consequence of the effort to reduce costs:

\begin{abstract}
"We're probably of the view that airlines, like any other businesses, are trying to minimise their costs and obviously that's impacting some of the services they provide their passengers and customers. ... So, there's probably a disconnect there in terms of what the passengers want and what the airlines want. Noting that there obviously is a link that the airlines are trying to keep the passengers happy as much as they can. Obviously, there's [sic] some commercial decisions that come into play, which impact that."
\end{abstract}

These statements indicate that the airlines' behaviour during the negotiations might be primarily driven by their specific strategies that can, but do not necessarily, represent passengers' interests. For example, low-cost carriers might primarily focus on operational efficiency over the cost of passenger convenience. Specific examples that illustrate the difference in interests between passengers and airlines include air bridges for increased passenger comfort, more convenient connection links between airport terminals, or a higher quality of service with improved waiting areas. Airlines might particularly decide against sunk investments that would improve the passenger experience but which would increase the airlines' dependency on an airport. In fact, the caution exercised in agreeing on investment was described by an airline executive:

\footnotetext{
"The airport wants to redevelop because it wants to represent the community and wants a nicer experience. We don't believe that's going to drive any incremental passenger traffic. It will be a nicer experience for the passengers, but there's no business case for us. [...] as an airline, we're happy to participate in investment, ... where it enhances capacity, or it gives us a competitive edge."
}

While this statement might indicate a disconnect between the airlines' and the passengers' interests, it must be noted that the power relationship between airports and airlines plays an important part in the 
commercial negotiations. Airports in Australia possess market power, which means that they are in a stronger position when negotiating new investments. It might be for this reason that airlines deter from committing to investments, specifically when those investments do not align with their strategy. As emphasised by an airport executive, "The airlines [sic] management job is not to act in the best interest of passengers ... their job is to act in the long-term interests of the airline". An academic confirmed that within the current regulatory environment, airlines must arguably focus primarily on their interests, which can be different from those of the passengers:

"[Airlines,] they've got their own agenda, their own business model. They need to make sure all their customers are happy and all the rest of it. But customers' needs can be quite different to what the airline wants."

Therefore, the question can be asked as to who represents passengers as the end-user of many aviation-related services. Based on the findings, it could be argued that airlines' interests are not necessarily aligned with passengers' interests because the airlines might pursue a strategy that is focused on operational efficiency rather than on passenger convenience. Passengers can choose between different airlines and the service package that aligns with their own individual preferences (e.g., low-cost carriers operating from a low-cost terminal vs full-service carrier including lounge access and priority check-in). It should be noted, however, that in Australia there is a duopoly with Virgin Australia Holdings and the Qantas Group dominating the domestic market, which might allow Australian airlines to not always focus on the passengers' interests.

Unlike airlines, passengers generally cannot choose between airports, and in Australia, not even between different modes of transport owing to the long distances between the main population centres. Consequently, airports possess a significant market power that can allow them to pursue their interests. The net effect of this situation is explained by an aviation consultant: "The current regime ... does get us to a point where it does work to a point. ... At the end of the day, they [passengers] have to rely on the fact that the airlines are doing the right thing for them." As underscored by this statement, the only option available to passengers within the current regulatory environment is to rely on airlines 
as their representatives. Following from the findings, however, this seems to be problematic because the airlines' behaviour might not be in line with the passengers' specific needs and willingness to pay. This leads to an important question: how might passengers be meaningfully represented during the commercial negotiations between airport operators and airlines? This question is addressed in the next section.

\section{Integrating the passengers' voice}

Different views emerged between the interviewed experts as to how the passengers' voice could be integrated into the commercial negotiations. Some noted that passengers are represented indirectly by means of surveys conducted by the airports and the ACCC, as well as from insights generated from community consultations. Also, some experts suggested social media as a possible medium for passengers to express their opinions, as explained by an aviation consultant: "They are looking at their surveys and their customers' satisfaction reports, and how they're seen on, certainly, social media et cetera. So, the passengers do have a voice."

The experts also noted that there is no requirement that feedback from passengers and the broader community be incorporated into the negotiations, and that in any case, there is no guidance on how this could be done systematically. As stated by an airport executive:

\footnotetext{
"The airports already survey the passengers as part of their quality of service reporting ...

so I think that part already works, but how that relates to the negotiation by the airline is

different. ... it's an interesting concept. I'm not sure how you'd go about it in practice."
}

This means that although surveys are performed and the results considered when it comes to the commercial negotiations between the airlines and the airport operators, the passengers have no voice as further confirmed by an aviation consultant: "They don't have a voice at the table with the airports, airlines". This seems to suggest that while passengers are listened to; their voice is not necessarily incorporated into the negotiations. 
In exploring possible options, some airport CFOs suggested that if the passenger survey results were officially part of the commercial negotiations, they would be beneficial and justify further investments as explained by an airport executive:

"It's probably in an airport's interest for that sort of feedback to form part of the equation because customers want customer service. The longer term, that probably helps us, helps justify more assets, more investment."

In other words, the direct integration of passenger surveys results into the negotiation could potentially strengthen an airport's position because passengers would push for a higher level of customer service. This increased negotiation power, in addition to the already existing market power, would mean that commercial-like negotiations are not possible because airports could use passenger surveys to justify new investments and higher airport charges. While this would be in airports' interest, particularly for those that are monitored by the ACCC regarding their quality of service, airlines see little value in these changes. This is because any increase in airport charges could reduce the revenue of airlines, especially if the route is dependent on price-sensitive customers. Apart from that, survey results might not necessarily align with the passengers' actual behaviour and willingness to pay. As a consequence, survey results should not be used as a reliable indicator of what investments passengers want and are willing to pay, and thus should not be considered as a mandatory element during commercial negotiations.

Continuing to explore possible options for incorporating passengers' voices, one airline executive stated that he does not think that the regulatory framework should give passengers the opportunity to have direct input into the negotiations: "the framework itself, I would think not". The interviewee saw the direct involvement of the passengers as impractical: "I think in terms of a direct involvement by consumers, that would be very difficult to manage”. These difficulties can be related to the diversity of the consumer base of both the airlines and the airports. The direct involvement of passengers would immensely increase the complexity of negotiations because of the passengers' different needs and interests. A possible solution to this problem might be the involvement of a 
spokesperson or a representative group for passengers, as suggested by an academic: "The passengers need to have some sort of group, or some sort of spokesperson for them or they need to represent themselves because I see their interests as quite different to those of the airline". This statement is in line with the above findings, namely that the interests of passengers and airlines are not necessarily the same. Hence, appointing a spokesperson for passengers or establishing a passenger representation group is a possible solution to keep the increase of the complexity during negotiations to a minimum. Also, it would alleviate the potential challenges of having passenger survey results alone officially incorporated into the commercial negotiations. A solution to the issue of having passengers with different interests might be the implementation of the direct charge mechanism. This alternative to the current charging system is analysed in the following section.

\subsection{Direct charge}

\section{Perception of the direct charge mechanism}

A common theme among the interviewees was the perception that the concept of airports directly charging passengers might be an interesting alternative to the current system. In fact, it was viewed as providing a possible way to bypass some of the investment-related negotiations between airlines and airports. As one expert representing an airport lobbying association described:

\footnotetext{
“I know it happened overseas at certain airports. They’ve done a passenger direct charging mechanism for certain infrastructure upgrades. I certainly think it's something that's worth exploring here, particularly if they don't want to go through the whole negotiation process for an airline."
}

In contrast, other experts were more critical, especially because of practical and cost reasons. Instead of the airlines collecting the airport charges, new processes would have to be implemented to facilitate an effective collection and control of airport charges. As highlighted by an aviation consultant, these additional processes and investments would increase the overall costs: 
“That really doesn't work. Once again, the cost of collecting it when the airline's already collecting it would diffuse a lot of it. You'd have to collect more because of the infrastructure that you would build into it; and having [sic] people there ticking and flicking and getting money out of people.... So, you're going to have a booth or some process to check it and monitor it, et cetera, at all airports."

This statement suggests that the possible benefits of airports directly charging passengers would not be justifiable by the higher overall costs for the same service level. Also, the direct charge mechanism would increase the market power possessed by airports, as one academic highlighted:

"Well, I think that what would happen is that the airport would be having more market power because - and when you see it, Melbourne Airport has significantly increased its parking fees in the last ten years, but not its landing fees. So, what's happening is that airports are realising, particularly in places like Melbourne, that they can basically - they are stronger at negotiating with the passenger than with the airline."

This means that the implementation of a direct charge mechanism would further increase the market power of airports on top of their already strong position. If there were no direct counterpart representing the passengers during the negotiations, the airport operators would have a free hand, as is the case with the parking fees. Apart from practicability, cost and market power issues, several experts also suggested that direct charge might have a negative impact on the airport or even travel experience of the passenger. As explained by an airline executive:

"However, going to the method of paying airport charges individually at the airport, it would significantly slow down throughput in the terminal, hamper the passenger experience and really get back to something that's 20 or 30 years in the past."

It could well be argued that processes that slow down the overall process at the airport and negatively impact the travel experience are not in passengers' interests. An airport CFO further expounded upon a reason for the negative impact on the passengers' experience: 
"Where the service is standard, and when the passenger isn't used to that approach because it doesn't happen anywhere, then it's considered very weak from a passenger experience point of view."

Processes that are different from most of the rest of the world would expose passengers, especially international ones, to an unfamiliar system, which could result in further slowing down airports' passenger-related processes. Technology advancements, however, could change the current perception and limitations of direct charge. For example, one airport executive pointed to recent developments in payment systems as a possible enabler of direct charge:

"Well, I guess that technology is going to be part of the answer because so much these days, over 90 percent of people travel with a mobile device. So, there's a facilitation aspect from the perspective of most people will be able to perhaps swipe a phone or a card or do something."

Technology advancements, such as developments in the area of mobile devices, might enable airports to explore alternative charging mechanisms. These developments might not resolve all of the issues identified above, however, especially those concerning increased market power.

\section{Direct charge for diversified services}

While the direct charge mechanism alongside with technology advancements might not work as an overall solution, there still might be possibilities for increased airport service diversification. Instead of airports directly charging the passenger for airport charges, experts suggested using the direct charging mechanism for add-on services. The range of ideas for direct charging ranged from providing different baggage services (e.g., door to door delivery) to diversified airport services (e.g., lounge usage, fast-track security checks, etc.). Technology developments, such as in the area of mobile devices, could smooth and accelerate implementation of this charging process. For example, an airport executive who is not in favour of airports collecting airport charges described the possibility of using the mechanism for add-on or diversified services: 
"However, for additional airport services - under a good, better, best model I think a direct charge is right. What do I mean by that? If you wish to go through immigration and security faster with a premium product, the options to have a direct charge I think are fair. If you want to go into a lounge, yes, I think that is a fair way of recovering. If you want a personalised concierge type model through an airport, I think that's a fair way of doing it. So, we're completely open to that and direct charges to passengers where there's a differentiated service."

An illustrative example of how this idea of direct charging add-on airport services might be realised is the new low-cost Terminal 4 at Melbourne Airport. The terminal represents the basic product of what a passenger requires when travelling through an airport. Accordingly, the airport prices are kept at a minimum to enable low-cost carriers to attract consumers who have a low willingness to pay. The basic service level, which the terminal provides, was described by an airline executive:

"[The] new low-cost carrier focused terminal that has a level of infrastructure that is appropriate to a low-cost operation and the price for that is a small increase on what we're currently paying, but the infrastructure we'll get in return will be far superior to the infrastructure that we've had in Melbourne previously."

Building on this basic product, which the passengers pay for via their airline ticket, could then be further diversified by means of offering add-on services to passengers with a higher willingness to pay. This would allow the passenger to choose the desired services and customise the travel experience. Ultimately, this would give passengers a voice in the service process because, while airports and airlines can independently negotiate investments that are required to ensure safety and operational efficiency, the airport can additionally decide to invest in add-on services based on their passengers' willingness to pay. 


\section{Discussion}

The present article investigated how passengers could be meaningfully represented in negotiations between airports and airlines. The article also explored the possibility of airports directly charging passengers as an alternative to the current system. In addition to a literature review on consumer representation in regulatory environments and direct charge, the article provided insights into how key stakeholders perceive the current regulatory environment surrounding the Australian air transport market and the passenger representation within it. Three important implications evolve from the research findings.

First, this research shows that within the Australian air transport market, passengers as endusers are faced with few choices and little power to express their needs. The long distances between the state capitals and lack of alternatives to air transport put passengers in a 'take it or leave it' position. Without an independent consumer representative, customers cannot place sufficient pressure on transport operators to provide an adequate service (Schiefelbusch, 2005). This situation is leveraged by the Australian aviation sector, which is dominated by two airline groups and lacks secondary airports, thus leaving passengers with even fewer choices. The latter implies that airport operators possess significant market power (Forsyth, 2004; 2008), which leads the airlines to take a cautious approach towards sunk investments (Biggar, 2012; D'Alfonso \& Nastasi, 2014; Serebrisky, 2003). Therefore, as a logical consequence and as also highlighted during the interviews, it seems that airlines mainly negotiate and invest in operational efficiency improvements, and do not see their role as one that contributes to investments that solely enhance the airport experience.

While airlines arguably indirectly represent the passenger during the commercial negotiations with airports, there appears to be a disconnect between airlines' and passengers' interests (cf. Littlechild, 2018). For example, while passengers might prefer and have the willingness to pay for investments that improve the quality of airport-related services, airlines might primarily focus on controlling their costs and investing in the improvement of their operational procedures (Lohmann \& 
Trischler, 2017). This means that airlines might not necessarily be good representatives for passengers when negotiating new commercial agreements with airports. In turn, the LHR does not define the representation of passengers during the negotiation of new infrastructure investments and related pricing decisions. In fact, there is no current requirement to incorporate the voice of the passengers (Productivity Commission, 2011). It is recommended here that policymakers more clearly specify the passengers' roles and influence within the current environment. This is because passengers represent a key stakeholder group within the air transport market and should therefore have a say in the future development of this market.

Second, and based on the finding that airlines might not necessarily represent passengers' interests, the current study reviewed alternatives to the current situation. One possible way to incorporate passengers' voices into the negotiations could be the integration of the passenger survey results. As highlighted by the interviewees, however, this approach could strengthen the airports' negotiation position. Specifically, airports could use passenger survey results to justify new investments and higher airport charges. The consequence is increased negotiating power by airports in addition to their existing market power, which subsequently can hinder commercial-like negotiations as a key objective of the LHR (Productivity Commission, 2011). In turn, the direct involvement of passengers would increase the complexity of the negotiation due to the diversity of the passenger market and needs. One possible solution to this problem could be the use of a spokesperson, a representative body (Harker et al., 2006), or a statutory watchdog that promotes passengers' interests through research-based evidence and public outreach (Thao, Wegelin \& von Arx, 2017). Such an approach would require consideration of whether the spokesperson or body is independent of the regulator and truly represents the voices of all passengers (Schiefelbusch, 2005; Tambini, 2012). Ultimately, this option would offer a practical way to represent the passenger more directly without substantially increasing the complexity of the negotiations.

Third, the present research explored the possibility of airports directly charging passengers as a way to bypass negotiations with airlines. This aspect was investigated in the context of ongoing technological advancements that constantly open new avenues for pricing methods. The findings 
suggest that direct charging might not be a desirable option for all parties involved, even with the advancements that the latest technologies have to offer. As noted by the interviewees, the implementation of direct charging mechanisms would lead to higher initial costs due to new processes and infrastructures, as well as negatively impact the customer experience, a viewpoint that is supported by De Neufville and Odoni (2013). Airports are transit hubs that accommodate passengers with a wide range of backgrounds and behavioural patterns (Pantouvakis and Renzi, 2016). Also, as experienced at other airports in the past, having charging processes in place that differ from those typically used by other airports can negatively impact the customer experience and slow down travel through the airport. Furthermore, experts suggested during the interviews that airports directly charging the passengers would increase the market power of airports because passengers are in a weaker negotiating position with the airport than are airlines. An illustration of this standpoint is the significantly higher increases in airport parking fees in comparison to its landing fees over the last ten years (ACCC, 2016), as well as the dearth of developments in areas that are not necessarily in the airlines' interest, such as landside access (e.g., paths, kerbside, traffic management) and connections between terminals (e.g., transfer options between international and domestic terminal). Because technological advancements might not solve this issue, the direct charging of passengers by airports is not deemed as a suitable alternative under the current LHR.

It might be possible, however, to use the direct charge mechanism for add-on or diversified airport services. Passengers typically differ in their specific needs and levels of willingness to pay (Martín et al., 2008). Hence, airport operators could offer and charge passengers directly for add-on services, and as such, customise the travel experience based on their willingness to pay. In this way, a basic negotiated airport service, which the passengers pay for via the airline ticket, could be further diversified. Yet, the development towards airports directly charging for diversified services is still in its infancy. Airports should explore the opportunities that new technology advancements can provide to the way services are provided and charged. Recent innovations, such as Android Pay, Apple Pay, smart watches, and payment apps, mean that direct charge for various services might be processed in a practical and convenient way, even for infrequent or international passengers. 


\section{Conclusion}

This paper reviewed passenger representation under the LHR that is currently in place in the Australian air transport market. Passenger representation is not defined within the LHR, indicating that passengers, as directly affected stakeholders, have little voice regarding what airport infrastructure is developed. The evaluation of the relevant literature and analysis of data obtained from in-depth interviews with selected key stakeholders shed light on the complexities involved in representing passengers more directly during commercial negotiations between airports and airlines. Also, new ways were explored as to how passengers might be more meaningfully represented during the commercial negotiations, thereby leading to important implications for scholars and policymakers.

This research is not without limitations, which lead to some important research avenues. Foremost, due to the qualitative nature of the research, the findings cannot be generalised. Also, the sample was restricted to a small number of participants and did not involve interviews or surveys with passengers. One opportunity for future research is to conduct a large-scale survey with passengers to investigate their perceived position within the Australian air transport market in comparison to other regulated markets, such as utilities and telecommunication. Moreover, this research focused on a very specific case, namely, the LHR as instantiated in Australia's four largest airports. Further research is required to investigate customer representation in other sectors or other regulatory environments. Thus, another interesting avenue could be to explore how an independent spokesperson or representative body might be effectively integrated into commercial negotiations. Finally, future studies might investigate how other sectors that are characterised by strong business-to-business relationships (e.g., IT, engineering, utilities) consider the end-users' needs during commercial negotiations, and whether technological advancements are used to charge for diversified products and services. 


\section{References}

ACCC (2014). Guideline for quality of service monitoring at airports. Canberra: Australian Competition and Consumer Commission. Retrieved March 04, 2018, from

https://www.accc.gov.au/regulated-infrastructure/airports-aviation/review-of-the-airport-quality-ofservice-monitoring-guideline-2013/final-guideline

ACCC (2016), Airport Monitoring Report 2014-15. Canberra: Australian Competition and Consumer Commission. Retrieved March 04, 2018, from https://www.accc.gov.au/publications/airportmonitoring-reports/airport-monitoring-report-2014-15

ACCC (2017). About us. Retrieved March 04, 2018, from Australian Competition \& Consumer Commission: https://www.accc.gov.au/about-us

ACA (2017). Our Customer Service Charter. Retrieved March 04, 2018, from http://www.airlinecustomeradvocate.com.au/General/ACACustomerCharter.aspx

Adler, N., Forsyth, P., Mueller, J., \& Niemeier, H.-M. (2015). An economic assessment of airport incentive regulation. Transport Policy, 41, 5-15. https://doi.org/10.1016/j.tranpol.2015.03.008

Arblaster, M. (2014). The design of light-handed regulation of airports: Lessons from experience in Australia and New Zealand. Journal of Air Transport Management, 38, 27-35.

https://doi.org/10.1016/j.jairtraman.2013.12.015

Arblaster, M. (2016). Negotiate-arbitrate regulation of airport services: Twenty years of experience in Australia. Journal of Air Transport Management, 51, 27-38.

https://doi.org/10.1016/j.jairtraman.2015.11.004

Arblaster, M. (2017). Light-Handed Regulation of Airport Services: An Alternative Approach to Direct Regulation?, in John D. Bitzan, James H. Peoples (ed.) The Economics of Airport Operations (Advances in Airline Economics, Volume 6) Emerald Publishing Limited, pp.15 - 47

Arblaster, M., \& Hooper, P. (2015). Light handed regulation - Can it play a role in the developing world? Transport Policy, 43, 32-41. https://doi.org/10.1016/j.tranpol.2015.05.014

Biggar, D. (2012). Why regulate airports? A Re-examination of the rationale for airport regulation. Journal of Transport Economics and Policy (JTEP), 46(3), 367-380.

http://www.jstor.org/stable/24396317

Bilotkach, V., Clougherty, J. A., Mueller, J., \& Zhang, A. (2012). Regulation, privatization, and airport charges: Panel data evidence from European airports. Journal of Regulatory Economics, 42(1), 73-94. http://dx.doi.org/10.1007/s11149-011-9172-1

CAA Consumer Panel (2013). Consumer Panel Annual Report 2013 (Report CAP 1094). Retrieved March 04, 2018, from The National Archives:

http://webarchive.nationalarchives.gov.uk/20140718102852/http://www.caa.co.uk/application.aspx?c atid $=33 \&$ pagetype $=65 \&$ appid $=11 \&$ mode $=$ detail $\& i d=5789$

CAA Consumer Panel (2017). CAA consumer panel. Retrieved March 04, 2018, from Civil Aviation Authority UK: https://www.caa.co.uk/Our-work/About-us/CAA-consumer-panel/

Cartledge, J. (1992). Consumer representation in public transport. In Public Transport Planning and Operations. Proceedings of the PTRC European Transport, Highways and Planning 20th Summer 
Annual Meeting. 14-18 September 1992, pp. 183-193, University of Manchester Institute of Science and Technology, UK.

D'Alfonso, T. \& Nastasi, A. (2014). Airport-Airline interaction: some food for thought. Transport Reviews, 34 (6), 730-748.

https://doi.org/10.1080/01441647.2014.971470

De Neufville, R. \& Odoni, A. (2013). Airport systems: planning, design and management (2nd ed.). New York, NY: McGraw-Hill Education.

Forsyth, P. (2004). Replacing regulation: airport price monitoring in Australia. In: Forsyth, P., Gillen, D., Knorr, A., Mayer, O., Niemeier, H.-M., Starkie, D. (Eds.), The Economic Regulation of Airports: Recent Developments in Australasia, North America and Europe. Ashgate, Aldershot.

Forsyth, P. (2008), Airport policy in Australia and New Zealand: Privatization, light-handed regulation, and performance. In C. Winston \& G. de Rus (Eds.), Aviation Infrastructure Performance: A Study in Comparative Political Economy (pp. 65-99). Washington, DC: Brookings Institution Press.

Fu, X., Homsombat, W., \& Oum, T.H. (2011). Airport-airline vertical relationships, their effects and regulatory policy implications. Journal of Air Transport Management, 17(6), 347-353.

https://doi.org/10.1016/j.jairtraman.2011.02.004

Gillen, D. (2011). The evolution of airport ownership and governance. Journal of Air Transport Management, 17(1), 3-13.

https://doi.org/10.1016/j.jairtraman.2010.10.003

Graham, A. (2014). Managing Airports: An international perspective (4th ed.). London, UK:

Routledge.

Hanson, M. (1999). Exit or voice? The prospects for public transport user representation in Israel. World Transport Policy and Practice, 5(4), 36-41.

Harker, M., Mathieu, L., Waddams Price, C. (2006). Regulation and Consumer Representation. In M. Crew \& D. Parker (Eds.), International handbook on economic regulation (pp. 209-231). Cheltenham, UK: Edward Elgar.

Littlechild, S.C. (2012). Australian airport regulation: Exploring the frontier. Journal of Air Transport Management, 21, 50-62.

https://doi.org/10.1016/j.jairtraman.2011.12.017

Littlechild, S. (2018). Economic regulation of privatised airports: Some lessons from UK experience. Transportation Research Part A: Policy and Practice, in Press. https://doi.org/10.1016/j.tra.2018.01.024

Lohmann, G., \& Trischler, J. (2017). Licence to build, licence to charge? Market power, pricing and the financing of airport infrastructure development in Australia. Transport Policy, 59, 28-37. https://doi.org/10.1016/j.tranpol.2017.06.009

Malina, R., Albers, S., \& Kroll, N. (2012). Airport incentive programmes: a European perspective. Transport Reviews, 32(4), 435-453.

https://doi.org/10.1080/01441647.2012.684223 
Martín, J. C., Román, C., \& Espino, R. (2008). Willingness to Pay for Airline Service Quality.

Transport Reviews, 28(2), 199-217.

http://dx.doi.org/10.1080/01441640701577007

Pantouvakis, A., \& Renzi, M.F. (2016). Exploring different nationality perceptions of airport service quality. Journal of Air Transport Management, 52, 90-98.

https://doi.org/10.1016/j.jairtraman.2015.12.005

Porter, M. E. (1979). How competitive forces shape strategy. Harvard Business Review, 57(2), 137145 .

Productivity Commission (2011). Economic Regulation of Airport Services, Inquiry Report no. 57, Canberra.

Schiefelbusch, M. (2005). Citizens' involvement and the representation of passenger interests in public transport: Dimensions of a long-neglected area of transport planning and policy with case studies from Germany. Transport Reviews, 25(3), 261-282.

http://dx.doi.org/10.1080/0144164042000335904

Schiphol (2017). Privium. Retrieved March 04, 2018, from https://www.schiphol.nl/en/privium/

Serebrisky, T. (2003). Market power: Vertical integration between airports and airlines. In The World Bank Group: Public policy for the private sector, note, n. 259.

Tambini, D. (2012). Consumer representation in UK communications policy and regulation. Info, 14(2), 3-16.

https://doi.org/10.1108/14636691211204833

Thao, V. T., Wegelin, P., \& von Arx, W. (2017). Are statutory passenger watchdogs effective in representing passenger interests in public transport? Transport Policy, 58, 1-9.

https://doi.org/10.1016/j.tranpol.2017.04.008

Trischler, J., \& Charles, M. (2018). The application of a service ecosystems lens to public policy analysis and design: Exploring the frontiers. Journal of Public Policy \& Marketing, in Press. https://doi.org/10.1509/jppm.17.060

Trischler, J. \& Lohmann, G. (2018) Monitoring quality of service at Australian airports: A critical analysis. Journal of Air Transport Management, 67, 63-71.

https://doi.org/10.1016/j.jairtraman.2017.11.004

Wittmer, A. \& Maurer, T. (2015). Airport loyalty programs. Paper presented at the 19th ATRS Conference, Singapore.

Yang, H., Fu. X. (2015). A comparison of price-cap and light-handed airport regulation with demand uncertainty. Transportation Research Part B, 73, 122-132. https://doi.org/10.1016/j.trb.2015.02.002

Yang H., Zhang A., \& Fu X. (2015). Determinants of airport-airline vertical arrangements: Analytical results and empirical evidence. Journal of Transport Economics and Policy, 49(3), 438-453.

Yin, R. K. (2016). Qualitative research from start to finish (2nd ed.). New York, NY: The Guilford Press. 
Table 1. Overview of the interviewed participants

\begin{tabular}{clll} 
ID & Background & Description of respondents' background & Data source \\
\hline 1 & Airline & Executive of a low-cost carrier & Transcript only \\
2 & Airline & Executive of a leading airline group in Australia & Transcript and notes \\
3 & Airline & Executive of a leading airline group in Australia & Transcript only \\
4 & Airline & $\begin{array}{l}\text { Executive of an international airline group } \\
\text { operating in Australia }\end{array}$ & Transcript only \\
& & Executive of a regional airline & Notes only \\
5 & Airline & Representative of an aviation association & Transcript and notes \\
6 & Airline & Representative of an airline association & Notes only \\
7 & Airline & Representative of an airport association & Transcript and notes \\
8 & Airport & CFO of a predominantly low-cost airport & Transcript and notes \\
9 & Airport & CFO of a capital city airport & Transcript only \\
10 & Airport & CFO of a capital city airport & Transcript and notes \\
11 & Airport & CFO of a capital city airport & Transcript only \\
12 & Airport & CFO of a major airport in New Zealand & Transcript and notes \\
13 & Airport & CFO of a capital city airport & Transcript and notes \\
14 & Airport & CFO of a capital city airport & Transcript and notes \\
15 & Airport & Representative of a regulatory agency & Notes only \\
16 & Other & Representative of an aviation consulting company & Transcript and notes \\
17 & Other & Representative of a regulatory agency & Notes only \\
18 & Other & Academic with expertise in the topic & Transcript and notes \\
19 & Other & Academic with expertise in the topic & Transcript only \\
20 & Other & Academic with expertise in the topic & Transcript only \\
21 & Other & & \\
\hline
\end{tabular}


Table 2. Overview of statements provided by interviewees from the different stakeholder groups

Airlines

$\approx \quad$ Airlines do represent passengers.

Airlines understand the passengers' needs because they have direct contact and get positive as well as

negative feedback from them.

Airlines support investments because the passenge experience at the airport affects the whole trave experience.

Airlines have a better understanding of the whole system underlying a passenger's travel journey

New ways are not feasible:

¿. Passenger surveys conducted by airports are not an option because they could lead to biased claims made by the airport operator.

It would be difficult to manage any form of direct passenger involvement during the negotiations -

छ negotiations are already lenghy and conplicated.

氖

\section{Positive:} $\begin{array}{cl} & \text { Direct charge would make it easier for the airline and } \\ \text { increase the transparency in terms of the airport }\end{array}$ charges.

Negative:

Direct charge is unlikely to be practicable, which would mean that the travel experience for the passenger would be negatively affected

ossibilities include:

Direct charge could be used for providing lounge access to infrequent passengers
Airlines do not represent passengers:

Airports

It is not the airline's job to represent the passenger; in fact, airlines focus on their own interests, which can diverge from passengers' needs (e.g., productivity vs. comfort).

Airlines are self-interested and want the lowest price, even if it means sacrificing some passenger experience - they pursue a short-term focus.

\section{New ways should be explored:}

Airport passenger surveys give passengers a voice, but these are not used during negotiations - only international airlines are interested in the passenger survey results.

It is in the airport's interest to incorporate passengers' voices because providing high customer service is key to its operations.

Opinions could be integrated from consultation forums and feedback from passengers and the broader community.

\section{Positive:}

Direct charge could provide a possibility to bypass the partly lengthy negotiatio processes.

The mechanism has worked to a certain extent at other places/airports.

Direct charge provides an opportunity to invest in and directly charge for services that airlines do not agree on

Negative:

Negative:
Direct charge would slow down processes and thus the passenger at the airport. Direct charge is not a practicable solution for standardised services because the passenger is not used to this process and therefore it would lead to a negative

\section{Possibilities include:}

Direct charge provides an opportunity for service innovation and customise services (e.g., faster processing at security, or premium services such as lounge access or door-to-door bag services)

It can allow the airport to unbundle the airport product into packages provided to different customer groups (e.g., business vs leisure travellers).
Others

Airlines do represent passengers:

Airlines do represent the interests of the passenger up to a point,

especially in terms of keeping airport charges low.

Airlines do not represent passengers: Airlines do not represent the passenger because they follow their own agenda which can be different from the passengers' needs.

\section{New ways should be explored:}

Passengers have currently no voice during negotiations because they must rely on the airlines as representatives although interests might diverge.

Airport passenger surveys are an option but have limitations in terms of reliability and representativeness of the actual needs.

Social media gives passengers a voice because it puts pressure on airlines and airports.

A spokesperson or a passenger representation group could be used. Negative:

Direct charge would make airports more expensive because of the implementation and maintaining of new processes.

The passenger experience would be negatively affected because of he 'uniqueness' of this approach in comparison to other countries and airports.

Direct charge would give the airports more market power because it implies that airports would negotiate investments/charges with passengers rather than airlines (passengers have less negotiation power than do airlines)

\section{Possibilities include:}

Direct charge provides an opportunity for airports to differentiate their product for the passengers' specific needs and willingness to pay. 


\section{Highlights}

- Passengers are dependent on airlines as a representative body

- Airlines and passengers do not necessarily share the same needs and interests

- Within the current duopoly in Australia passengers have little voice

- Directly charging the passengers for the airport fees is not a suitable alternative

- An independent representation body could help to increase the passengers' influence 


\section{Accepted Manuscript}

Passenger representation within the light-handed regulation - Insights from the Australian air transport market

Beat Kistler, Jakob Trischler, Gui Lohmann

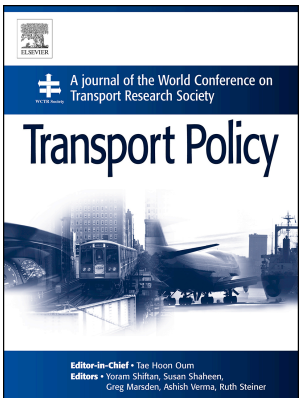

PII:

S0967-070X(18)30206-3

DOI:

10.1016/j.tranpol.2018.09.008

Reference: JTRP 2067

To appear in: Transport Policy

Received Date: 8 March 2018

Revised Date: 20 July 2018

Accepted Date: 7 September 2018

Please cite this article as: Kistler, B., Trischler, J., Lohmann, G., Passenger representation within the light-handed regulation - Insights from the Australian air transport market, Transport Policy (2018), doi: 10.1016/j.tranpol.2018.09.008.

This is a PDF file of an unedited manuscript that has been accepted for publication. As a service to our customers we are providing this early version of the manuscript. The manuscript will undergo copyediting, typesetting, and review of the resulting proof before it is published in its final form. Please note that during the production process errors may be discovered which could affect the content, and all legal disclaimers that apply to the journal pertain. 